\title{
Solvothermal Synthesis of ZnO Nanoparticles for Photocatalytic Degradation of Methyl Orange and $p$-Nitrophenol
}

\author{
Ying Wang ${ }^{1,+}$, Chuanxi Yang ${ }^{2,+}$, Yonglin Liu ${ }^{2}$, Yuqi Fan ${ }^{1}$, Feng Dang ${ }^{3}$, Yang Qiu ${ }^{1}$, Huimin Zhou ${ }^{1}$, \\ Weiliang Wang ${ }^{2, *}(\mathbb{D})$ and Yuzhen Liu ${ }^{4, *}$ \\ 1 Institute of Environment and Ecology, Shandong Normal University, Jinan 250358, China; \\ wangying8071@163.com (Y.W.); yuqifan@sdnu.edu.cn (Y.F.); qy19982021@163.com (Y.Q.); \\ zhm9689z@163.com (H.Z.) \\ 2 School of Environmental and Municipal Engineering, Qingdao University of Technology, \\ Qingdao 266525, China; yangchuanxi1989@hotmail.com (C.Y.); liuyonglin2010@163.com (Y.L.) \\ 3 Key Laboratory for Liquid-Solid Structural Evolution and Processing of Materials, Shandong University, \\ Jinan 250061, China; dangfeng@sdu.edu.cn \\ 4 College of Geography and Environment, Shandong Normal University, Jinan 250358, China \\ * Correspondence: sdqcsdnu@163.com (W.W.); yzhliu320@126.com (Y.L.); Fax: +86-0532-85071262 (W.W.); \\ +86-0531-86181939 (Y.L.) \\ + These authors are co-first authors on this work.
}

\section{check for} updates

Citation: Wang, Y.; Yang, C.; Liu, Y.; Fan, Y.; Dang, F.; Qiu, Y.; Zhou, H.; Wang, W.; Liu, Y. Solvothermal Synthesis of $\mathrm{ZnO}$ Nanoparticles for Photocatalytic Degradation of Methyl Orange and $p$-Nitrophenol. Water 2021, 13, 3224. https://doi.org/ $10.3390 / w 13223224$

Academic Editors: Andreas N. Angelakis, Weihua Zhao, Kai Wang and Shanyun Wang

Received: 9 October 2021

Accepted: 9 November 2021

Published: 13 November 2021

Publisher's Note: MDPI stays neutral with regard to jurisdictional claims in published maps and institutional affiliations.

Copyright: (c) 2021 by the authors. Licensee MDPI, Basel, Switzerland. This article is an open access article distributed under the terms and conditions of the Creative Commons Attribution (CC BY) license (https:/ / creativecommons.org/licenses/by/ $4.0 /)$.

\begin{abstract}
The photocatalytic degradation of organic pollutants is an effective method of controlling environmental pollution. $\mathrm{ZnO}$ nanoparticles (ZnO NPs) were prepared by the solvothermal method and characterized by scanning electron microscopy (SEM), energy dispersive spectroscopy (EDS), X-ray diffraction (XRD), X-ray photoelectron spectroscopy (XPS), and UV-visible diffuse reflectance spectroscopy (UV-Vis DRS). The results showed that the ZnO NPs had a uniform size of $25-40 \mathrm{~nm}$, hexagonal wurtzite structure, and a band gap of $2.99 \mathrm{eV}$. The photocatalytic degradation of methyl orange (MO) and $p$-nitrophenol (PNP) was used as a model reaction to evaluate the photocatalytic activity of ZnO NPs. The photocatalytic degradation rates (pseudo-first-order kinetics) of MO and PNP were $92 \%\left(0.0128 \mathrm{~min}^{-1}\right)$ and $56.2 \%\left(0.0042 \mathrm{~min}^{-1}\right)$, respectively, with a $25 \mathrm{~W}$ ultraviolet lamp, MO $/ \mathrm{PNP}$ concentration $=20 \mathrm{mg} / \mathrm{L}, \mathrm{ZnO} N \mathrm{Ns}$ dose $=1.5 \mathrm{~g} / \mathrm{L}$, and time $=180 \mathrm{~min}$. The photocatalytic mechanism of ZnO NPs and degradation pathways of MO and PNP were also proposed. The results provide valuable information and guidance for the treatment of wastewater via photocatalytic methods.
\end{abstract}

Keywords: $\mathrm{ZnO}$; solvothermal; methyl orange; $p$-nitrophenol

\section{Introduction}

Energy and environmental issues are the two major limitations that restrict the sustainable development of humankind and have become a focus for all countries in the world. Photocatalytic technology has become an important technical means of solving energy and environmental problems worldwide because of its ability to directly use sunlight to drive the photolysis of water to produce hydrogen, perform organic synthesis, and degrade pollutants [1]. Photocatalytic technology has several advantages. Photocatalysis uses green solar energy and mild reaction conditions, it is easy to operate, it can effectively reduce the consumption of nonrenewable energy, and it generates less secondary pollution than traditional chemical processes. Additionally, the semiconductor catalyst itself is nontoxic and harmless, easy to obtain, and stable; it exhibits performance and recyclability and has other advantages [2].

At present, semiconductor photocatalysts mainly include $\mathrm{TiO}_{2}, \mathrm{CdS}, \mathrm{ZnS}$, and $\mathrm{SiO}_{2}$. Among them, $\mathrm{TiO}_{2}$ is the most widely used. However, traditional $\mathrm{TiO}_{2}$ photocatalysts 
have a very low sunlight utilization rate [2]. During photocatalysis, the electron-hole pair recombination rate generated by the representative $\mathrm{TiO}_{2}$ is high. The large-scale application of traditional photocatalysts in actual water treatment is uneconomical, and these disadvantages limit the development prospects of traditional $\mathrm{TiO}_{2}$ photocatalysts. However, $\mathrm{ZnO}$, a new generation of direct band gap, wide-bandgap semiconductors, has a band gap of $3.37 \mathrm{eV}$, an exciton binding energy of $60 \mathrm{meV}$, and the advantages of simple preparation, high stability, and low cost [3]. $\mathrm{ZnO}$ is considered a suitable $\mathrm{TiO}_{2}$ substitute because its photodegradation mechanism has been proven to be similar to that of $\mathrm{TiO}_{2}$ [4] According to reports, $\mathrm{ZnO}$ is sometimes more efficient than $\mathrm{TiO}_{2}$, and its effect on advanced oxidation of bleaching wastewater from pulp mills and photocatalytic oxidation of phenol is especially remarkable [5,6]. Moreover, $\mathrm{ZnO}$ has a direct band gap and band edge position similar to those of $\mathrm{TiO}_{2}$, and the electron mobility is 10-100 times higher than that of $\mathrm{TiO}_{2}$, thereby reducing the efficiency of electron transfer [7]. Therefore, $\mathrm{ZnO}$ has been indicated to have great potential in a wide range of photocatalysis and photoelectrochemical applications. The methods for regulating the growth of nanostructured $\mathrm{ZnO}$ mainly include hydrothermal synthesis, chemical vapour precipitation, and the sol-gel method [8-10]. Common methods of improving the photocatalytic activity of $\mathrm{ZnO}$ include doping metals and nonmetals, depositing precious metals, constructing heterojunctions, and coupling carbon materials [11]. Yunlong Zhou prepared nano-ZnO/bamboo charcoal composites, which had a photocatalytic activity of $92.3 \%$ for the degradation of methyl orange (MO) under UV light for $40 \mathrm{~min}$ [12]. Umar prepared $\mathrm{ZnO}$ balls that had a photocatalytic activity of 100\% for the degradation of methylene blue (MB) under UV light over $70 \mathrm{~min}$ [13].

Although there are many methods of synthesizing $\mathrm{ZnO}$ nanomaterials, most of the synthesis methods have complicated steps, and some require surfactants or structuredirecting agents to control the morphology during synthesis. Moreover, the photocatalytic performance of $\mathrm{ZnO}$ and its relationships to size and morphology are not very clear thus far. Pengfei Cheng synthesized sea urchin-like layered $\mathrm{ZnO}-\mathrm{TiO}_{2}$ photocatalysts by a hydrothermal method. The $\mathrm{ZnO}-\mathrm{TiO}_{2}$ photocatalyst is a $3 \mathrm{D}$ urchin-shaped $\mathrm{TiO}_{2}$ nanosphere with $1 \mathrm{D} \mathrm{ZnO}$ nanospindles (UTZ) on the surface, ranging in diameter from $1.5 \mathrm{~mm}$ to $2.5 \mathrm{~mm}$. The degradation rate of $\mathrm{MO}$ by the $\mathrm{ZnO}-\mathrm{TiO}_{2}$ photocatalyst was up to $100 \%$ under UV lamp irradiation for $30 \mathrm{~min}$ [14]. Peng Zhang synthesized ZnO@C gemel hexagonal microrods with thin hydrothermal carbon (HTC) layers by a hydrothermal method. The rate of degradation of $\mathrm{ZnO} @ \mathrm{C}$ to $\mathrm{MB}$ was close to $100 \%$ within $40 \mathrm{~min}$ under UV lamp irradiation [15]. Rashidi synthesized $\mathrm{ZnO}$ nanostructures by a solvothermal (ethanol) method using molybdate phosphoric acid. When the conditions were changed, $100 \mathrm{~nm}$ nanoparticles and $250 \mathrm{~nm}$ microrod structures were synthesized. These particles showed high performance in the photocatalytic degradation of $\mathrm{MO}$ and decolorized by almost $100 \%$ in only 20 min [16,17].

Therefore, in this work, a simple solvothermal synthesis method without the introduction of surfactants and agents was used to prepare small ZnO NPs with a sphere-like morphology and a large visible response edge of $415 \mathrm{~nm}$. The specific objectives were (1) to prepare $\mathrm{ZnO}$ NPs via a solvothermal method, (2) to evaluate the photocatalytic activity of ZnO NPs by degradation of MO and $p$-nitrophenol (PNP), and (3) to propose the photocatalytic mechanism of $\mathrm{ZnO}$ NPs and degradation pathways of MO and PNP.

\section{Experimental}

\subsection{Reagents and Materials}

Dihydrate and zinc acetate $\left(\mathrm{Zn}(\mathrm{AC})_{2} \cdot 2 \mathrm{H}_{2} \mathrm{O}\right)$, sodium hydroxide $(\mathrm{NaOH})$, ethanol $\left(\mathrm{C}_{2} \mathrm{H}_{6} \mathrm{O}\right)$, and methyl orange $\left(\mathrm{C}_{14} \mathrm{H}_{14} \mathrm{~N}_{3} \mathrm{NaO}_{3} \mathrm{~S}, \mathrm{MO}\right)$ were purchased from Sinopharm Chemical Reagent Co., Ltd. P-nitrophenol (PNP) was purchased from Tianjin Damao Chemical Reagent Co., Ltd. All of these reagents were of AR grade and used without further purification. Deionized water was used to prepare all the solutions. 


\subsection{Preparation of $\mathrm{ZnO} N \mathrm{Ns}_{\mathrm{s}}$}

$\mathrm{ZnONPs}$ were prepared by the solvothermal method as follows: $0.22 \mathrm{~g} \mathrm{Zn}(\mathrm{AC})_{2} \cdot 2 \mathrm{H}_{2} \mathrm{O}$ and $0.064 \mathrm{~g} \mathrm{NaOH}$ were added to $80 \mathrm{~mL}$ ethanol, and the mixture was magnetically stirred at $80^{\circ} \mathrm{C}$ for $2 \mathrm{~h}$. A white precipitate gradually formed. The mixture was directly transferred to a $100 \mathrm{~mL}$ Teflon autoclave, sealed and stored at $180^{\circ} \mathrm{C}$ for $12 \mathrm{~h}$. After the reaction, the autoclave was cooled naturally to room temperature. The mixture was centrifuged and washed with deionized water and ethanol for more than 5 times. The solid precipitates were dried for $3 \mathrm{~h}$ in a high-temperature oven at $80^{\circ} \mathrm{C}$, calcined for $2 \mathrm{~h}$ in a muffle furnace at $400{ }^{\circ} \mathrm{C}$, cooled to room temperature, and ground to obtain $\mathrm{ZnO}$ NPs. Figure 1 shows the preparation process of $\mathrm{ZnO}$ NPs.

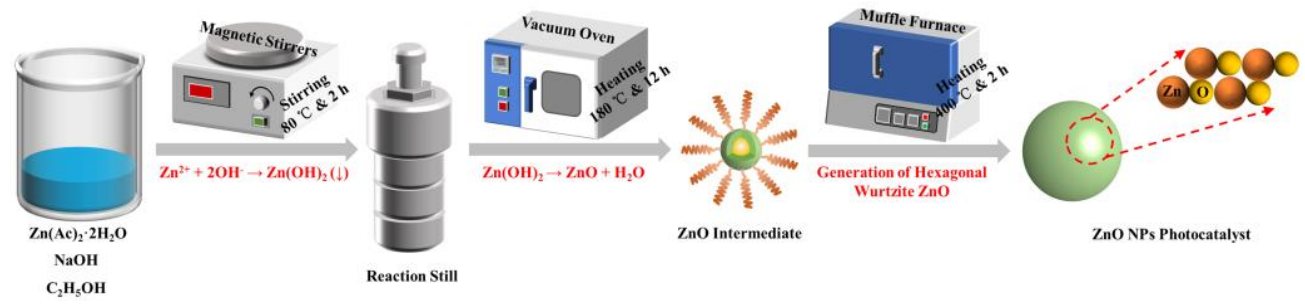

Figure 1. Preparation of $\mathrm{ZnO}$ NPs.

\subsection{Characterization of $\mathrm{ZnO} N \mathrm{NS}$}

Scanning electron microscopy (SEM) images with energy dispersive spectroscopy (EDS) were obtained on a QUANTA Q400 thermal-field emission scanning electron microscope and used to determine the morphology and aggregation status of the prepared $\mathrm{ZnO}$ NPs.

X-ray diffraction (XRD) patterns were recorded on a Bruker D8 Advance X-ray diffractometer with $\mathrm{Cu} \mathrm{K} \alpha$ radiation $(\lambda=1.5418 \AA)$ and used to determine the crystal structure and phase composition of the prepared ZnO NPs.

$X$-ray photoelectron spectroscopy (XPS) measurements were performed using a Thermo ESCALAB 250Xi system with an Al K $\alpha$ X-ray source. All of the binding energies were referenced to the $\mathrm{C} 1 \mathrm{~s}$ peak at $284.8 \mathrm{eV}$, which corresponded to the surface adventitious carbon.

Absorption spectra were obtained by UV-visible diffuse reflectance spectroscopy (UV-3600) using $\mathrm{BaSO}_{4}$ as a reference.

\subsection{Photocatalytic Activity Test}

The photocatalytic activity of ZnO NPs was monitored by the degradation of MO/PNP in aqueous solution. In all photocatalytic experiments, an appropriate amount of photocatalyst was added to $50 \mathrm{~mL}$ of MO/PNP solution at a concentration of $20 \mathrm{mg} / \mathrm{L}$. The samples were placed in a photocatalytic reaction apparatus and stirred magnetically in a dark room for $30 \mathrm{~min}$ to ensure adsorption balance. A $25 \mathrm{~W}$ ultraviolet lamp was used as the light source, and $1.5 \mathrm{~mL}$ equal samples were taken every $30 \mathrm{~min}$ to remove the particles by centrifugation. The absorbance of the filtrate was recorded on a TU-1900 ultraviolet spectrophotometer, on which the absorbance of $\mathrm{MO}$ was recorded at $\lambda=464 \mathrm{~nm}$ and that of PNP was recorded at $\lambda=317 \mathrm{~nm}$. Finally, the filtrate was analysed. According to the relationship between the absorbance and concentration, the concentration of MO was calculated according to the Beer-Lambert Law, and the removal rate (RR) was calculated as follows:

$$
R R=\left(C_{0}-C_{t}\right) / C_{0} \times 100 \%
$$

where $C_{0}$ is the initial concentration of $\mathrm{MO} / \mathrm{PNP}$ in water in $\mathrm{mg} / \mathrm{L}$, and $C_{t}$ is the mass concentration of MO/PNP in water when the reaction time is $t(\mathrm{~min})$ in $\mathrm{mg} / \mathrm{L}$. 


\section{Results and Discussion}

\subsection{Characterization of $\mathrm{ZnO} N \mathrm{NS}_{\mathrm{s}}$}

Morphology analysis: the morphology and structure of the obtained $\mathrm{ZnO}$ were characterized by SEM. Figure 2 shows that the diameter of $Z n O N P s$ was approximately $25-40 \mathrm{~nm}$. The grown nanoparticles were almost spherical. The particle size was relatively uniform, while the structure between the particles was loose, and there were many voids. This loose structure composed of nanoparticles is conducive to improving the photocatalytic performance of the material [18].
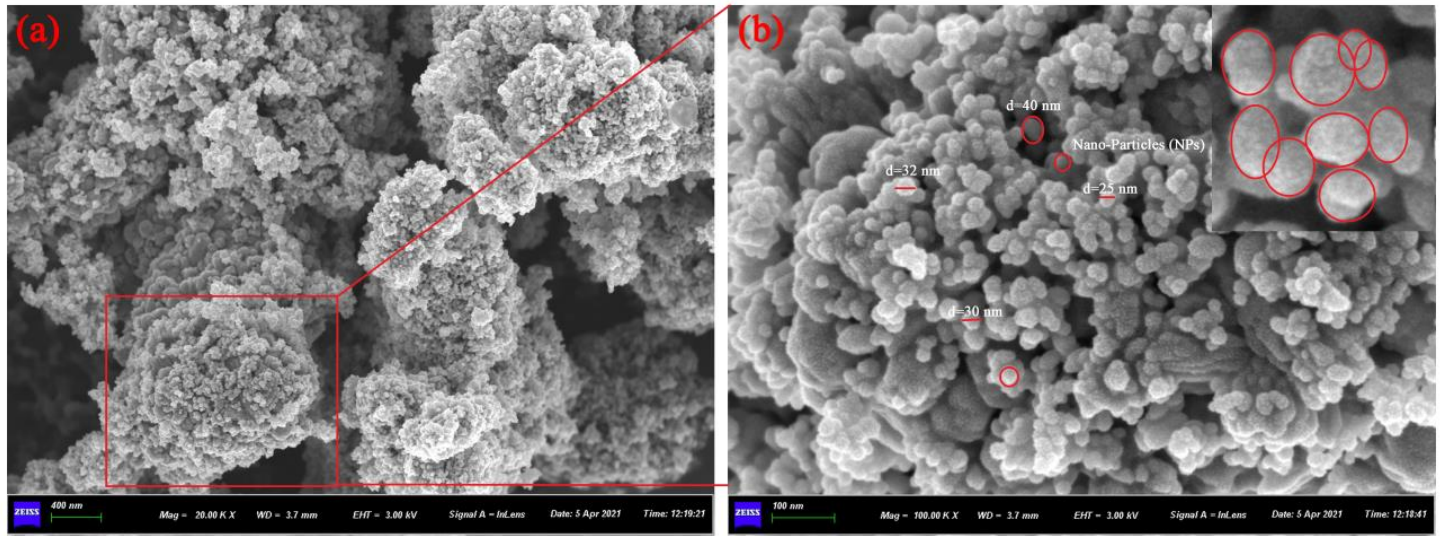

Figure 2. SEM images of ZnO NPs. (a) agglomeration, (b) nano-particles.

XRD pattern analysis: Figure 3a shows the XRD patterns of the ZnO NPs, which are consistent with the data in PDF no. 01-070-8070. The crystal structure and phase purity of the sample are demonstrated. The diffraction peaks at $2 \theta=31.8^{\circ}, 34.4^{\circ}, 36.3^{\circ}, 47.6^{\circ}, 56.6^{\circ}$, $62.9^{\circ}, 66.4^{\circ}, 68.0^{\circ}, 69.1^{\circ}$, and $72.6^{\circ}$ correspond to the (100), (002), (101), (102), (110), (103), (200), (112), (201), and (004) crystallographic planes, respectively. The sharp peaks imply a well-crystallized $\mathrm{ZnO}$ material. No additional impurity peaks were detected, indicating the high purity of the ZnO NPs. In this pattern, all the detectable peaks can be attributed to the hexagonal wurtzite structure. The grain size of $\mathrm{ZnO}$ NPs can be calculated by the Scherrer equation:

$$
D=K \lambda /\left(\cos \theta \cdot B_{1 / 2}\right)
$$

where $D$ is the grain size of the nanomaterial; $K$ is the Scherrer constant of the diffraction peak; the value of $\mathrm{ZnO}$ was equal to $0.89 ; \lambda$ is the wavelength of $\mathrm{X}$-ray, $0.15418 \mathrm{~nm} ; \theta$ is Bragg diffraction Angle; and $B_{1 / 2}$ is half the width of the diffraction peak [19]. According to the crystal plane of anatase (101) corresponding to ZnO NPs at $36.3^{\circ}$, the grain size of $\mathrm{ZnO}$ NPs is calculated as $0.1696 \mathrm{~nm}$. The grain size of $0.1696 \mathrm{~nm}$ is too small compared with the ZnO NPs particles obtained by SEM image $(25-40 \mathrm{~nm})$. This is due to the size of $\mathrm{ZnO}$ NPs from the SEM images being the agglomerates of unit cells $(0.1696 \mathrm{~nm}$ from XRD).

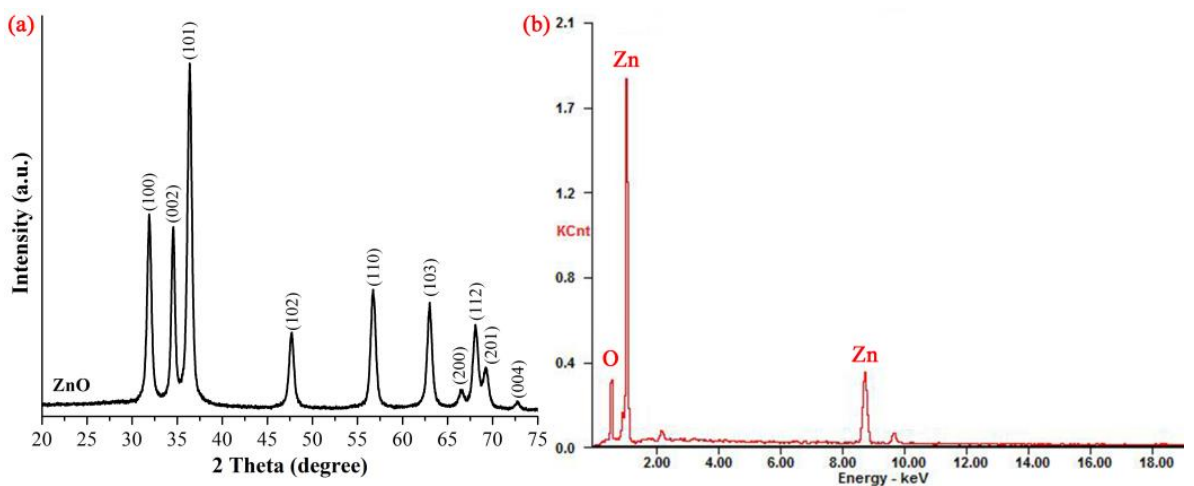

Figure 3. XRD patterns (a) and EDS (b) of ZnO NPs. 
Element composition: the EDS analysis results are shown in Figure $3 \mathrm{~b}$ and Table 1 . The $\mathrm{ZnO}$ NPs prepared by the solvothermal synthesis method only contained $\mathrm{Zn}$ and $\mathrm{O}$ and did not contain other impurities. The relative weight percentages of $\mathrm{Zn}$ and $\mathrm{O}$ in the $\mathrm{ZnO}$ NPs were $84.27 \%$ and $15.73 \%$, respectively, and the atomic percentages were 56.74 and $43.26 \%$, respectively. XPS was used to analyse the chemical state and elemental composition of the $\mathrm{ZnO} N P s$, and the results are shown in Figure 4. The percentages of $\mathrm{O}$ and $\mathrm{Zn}$ atoms in the $\mathrm{ZnO} N$ Ps were $39.16 \%$ and $41.28 \%$, respectively, which is close to a $1: 1$ ratio. As shown in Figure $4 \mathrm{~b}$, the $\mathrm{Zn} 2 \mathrm{p}$ spectrum of $\mathrm{ZnO}$ has two peaks at 1044.7 and $1021.5 \mathrm{eV}$, and the binding energy interval between these two lines is $23.2 \mathrm{eV}$, which is within the standard reference value range of the $\mathrm{ZnO}$ wurtzite structure. This result indicates that $\mathrm{Zn}$ ions are present in the normal $\mathrm{Zn}^{2+}$ valence state in the nanocomposites [20]. As shown in Figure 4c, the $\mathrm{O} 1 \mathrm{~s}$ spectrum of $\mathrm{ZnO}$ has two peaks at 531.4 and $529.9 \mathrm{eV}$. The main peak at $529.9 \mathrm{eV}$ is related to the lattice oxygen species $\left(\mathrm{O}^{2-}\right)$ in the $\mathrm{Zn}$-O bond of the wurtzite structure, while the main peak at $531.4 \mathrm{eV}$ is related to the chemically adsorbed oxygen species $\left(\mathrm{OH}^{-}\right)$. The relative surface hydroxyl content is 1.07. The $\mathrm{C} 1 \mathrm{~s}$ spectrum of $\mathrm{ZnO}$ in Figure $4 \mathrm{~d}$ has three peaks at $284.6 \mathrm{eV}, 286.2 \mathrm{eV}$, and $288.6 \mathrm{eV}$, as does the standard $\mathrm{C} 1 \mathrm{~s}$ spectrum that shows $(\mathrm{C}-\mathrm{C}),(\mathrm{C}=\mathrm{O})$, and $(\mathrm{O}-\mathrm{C}=\mathrm{O})$ bonds. There is no XPS signal corresponding to the $\mathrm{Zn}-\mathrm{C}$ bond in the $\mathrm{Zn} 2 \mathrm{p}$ orbital or the $\mathrm{C} 1 \mathrm{~s}$ orbital (approximately $281 \mathrm{eV}$ ), indicating that carbon is not doped in the ZnO NPs [21,22].

Table 1. Elementary composition of ZnO NPs according to EDS and XPS.

\begin{tabular}{ccc}
\hline ZnO NPs & At\% from EDS & At \% from XPS \\
\hline Zn & 56.74 & 41.28 \\
O & 43.26 & 39.16 \\
C & & 19.55 \\
Zn/O atomic ratio & 1.31 & 1.05 \\
\hline
\end{tabular}

(a)

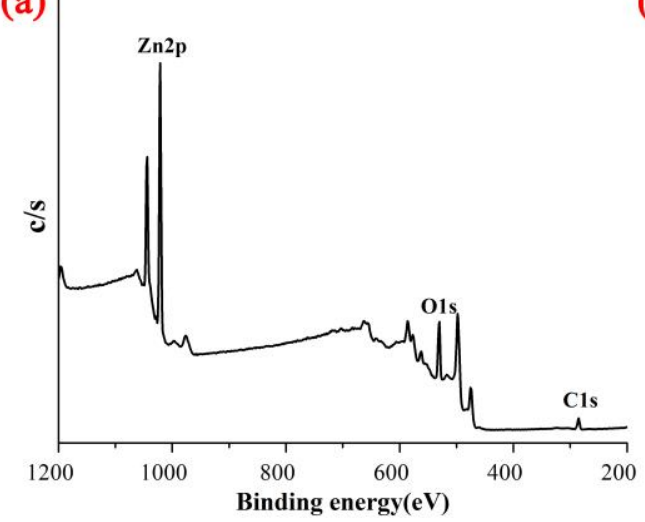

(c)

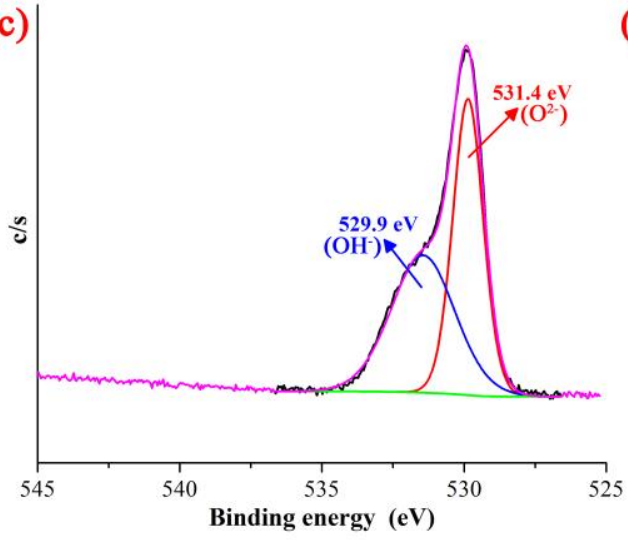

(b)

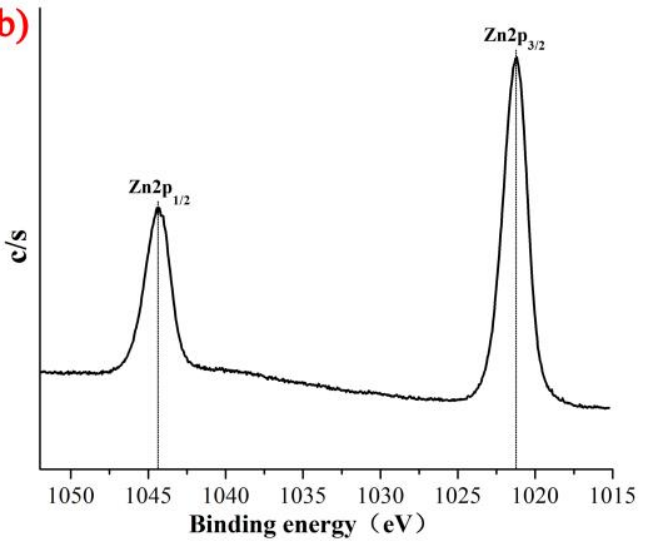

(d)

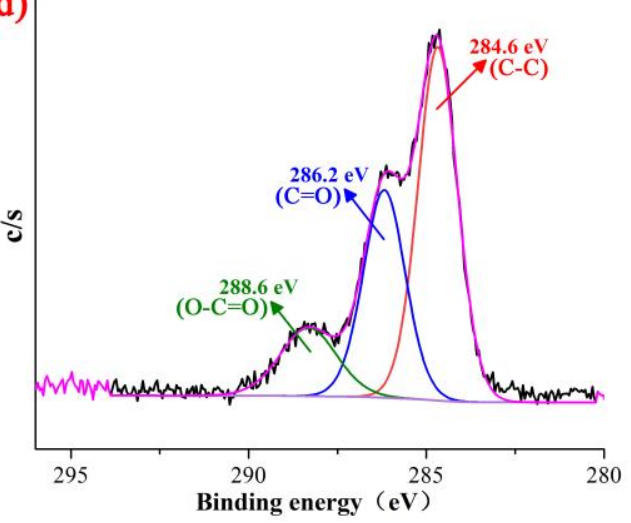

Figure 4. XPS spectra of ZnO NPs (a), Zn 2p (b), O 1s (c) and C 1s (d). 
UV-Vis DRS: Figure 5 shows the UV-Vis absorption spectra of the prepared ZnO NPs. $\mathrm{ZnO}$ has a strong response to UV light at wavelengths of less than $390 \mathrm{~nm}$ but has a low response in the visible light range at wavelengths of more than $390 \mathrm{~nm}$. The spectra display sharp, fundamental absorption in the ultraviolet-visible region with a band-gap absorption edge of $415 \mathrm{~nm}$, which can be assigned to the intrinsic band-gap absorption of $\mathrm{ZnO}$ due to the electronic transition from the valance band to the conduction band. According to the equation $E g=h c / \lambda=1240 / \lambda$ (where $h$ is the Planck constant $\left(4.13566743 \times 10^{-15} \mathrm{eV} \cdot \mathrm{s}\right), c$ is the light velocity $\left(3 \times 10^{8} \mathrm{~m} / \mathrm{s}\right)$ and $\lambda$ is the wavelength), the energy gap of ZnO NPs is $2.99 \mathrm{eV}$ [23].

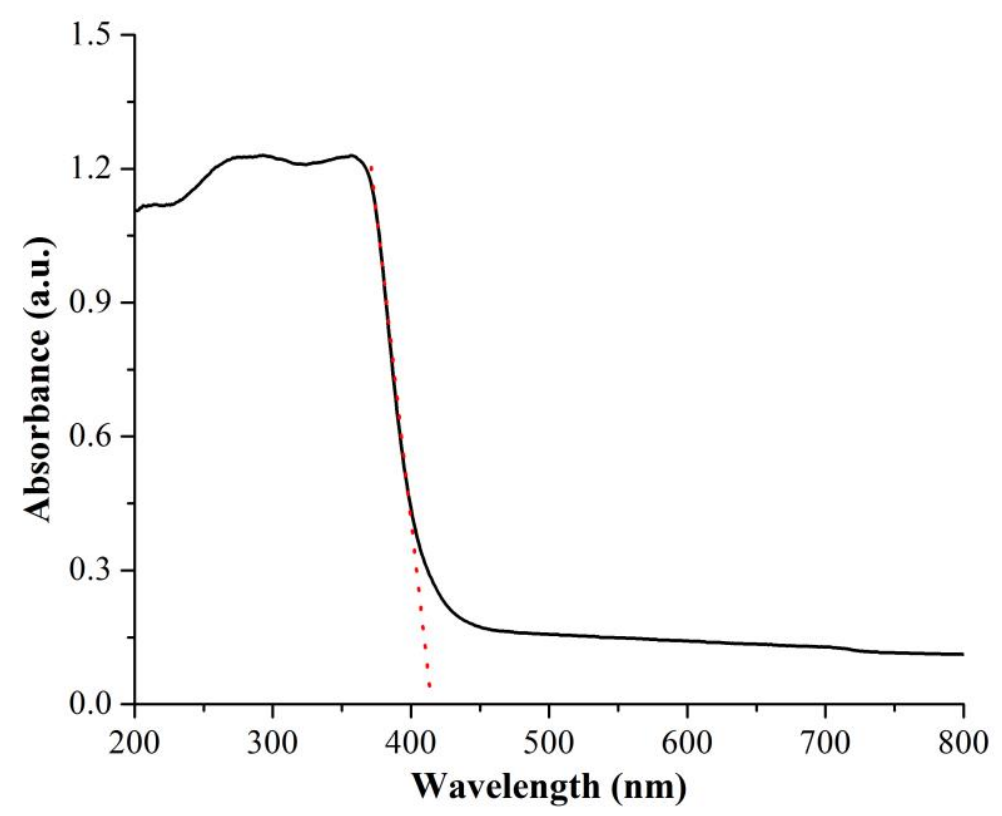

Figure 5. UV-Vis DRS of ZnO NPs.

\subsection{Photocatalytic Activity and Degradation Kinetics of $\mathrm{ZnO} N P s$}

The photocatalytic activity of ZnO NPs was evaluated by detecting the degradation of $\mathrm{MO}$ and PNP in aqueous solution under UV lamp irradiation. Figure 6a shows the photocatalytic degradation results of $\mathrm{MO}$ in the presence of $\mathrm{ZnO}$. The amount of catalyst is a very important factor in photocatalytic oxidation [24]. The mass concentration of $\mathrm{MO}$ was fixed at $20 \mathrm{mg} / \mathrm{L}$, and the dose of $\mathrm{ZnO}$ was changed to compare the influence on the degradation rate of MO after $180 \mathrm{~min}$, as shown in Figure 6a. The blank experiment without added catalyst showed that the degradation rate had no obvious change after reaction for $180 \mathrm{~min}$. The photodegradation rate of $\mathrm{MO}$ increased with an increasing $\mathrm{ZnO}$ dose in the range of $0.2-1.5 \mathrm{~g} / \mathrm{L}$. When the catalyst concentration was $2.0 \mathrm{~g} / \mathrm{L}$, the photodegradation rate of MO decreased with an increasing catalyst amount. Figure $6 \mathrm{~b}$ shows the photocatalytic degradation of PNP in the presence of $\mathrm{ZnO}$. The mass concentration of PNP was fixed at $20 \mathrm{mg} / \mathrm{L}$, and the dose of $\mathrm{ZnO}$ was changed to compare the influence of the $\mathrm{ZnO}$ dose on the degradation rate of PNP after $180 \mathrm{~min}$, as shown in Figure 6b. The blank experiment without catalyst showed that the degradation rate had no obvious change after reaction for $180 \mathrm{~min}$. The photodegradation rate of PNP increased with an increasing $\mathrm{ZnO}$ dose in the range of $0.2-1.5 \mathrm{~g} / \mathrm{L}$. When the catalyst dose was $2.0 \mathrm{~g} / \mathrm{L}$, the photodegradation rate of PNP decreased with an increasing catalyst amount. 

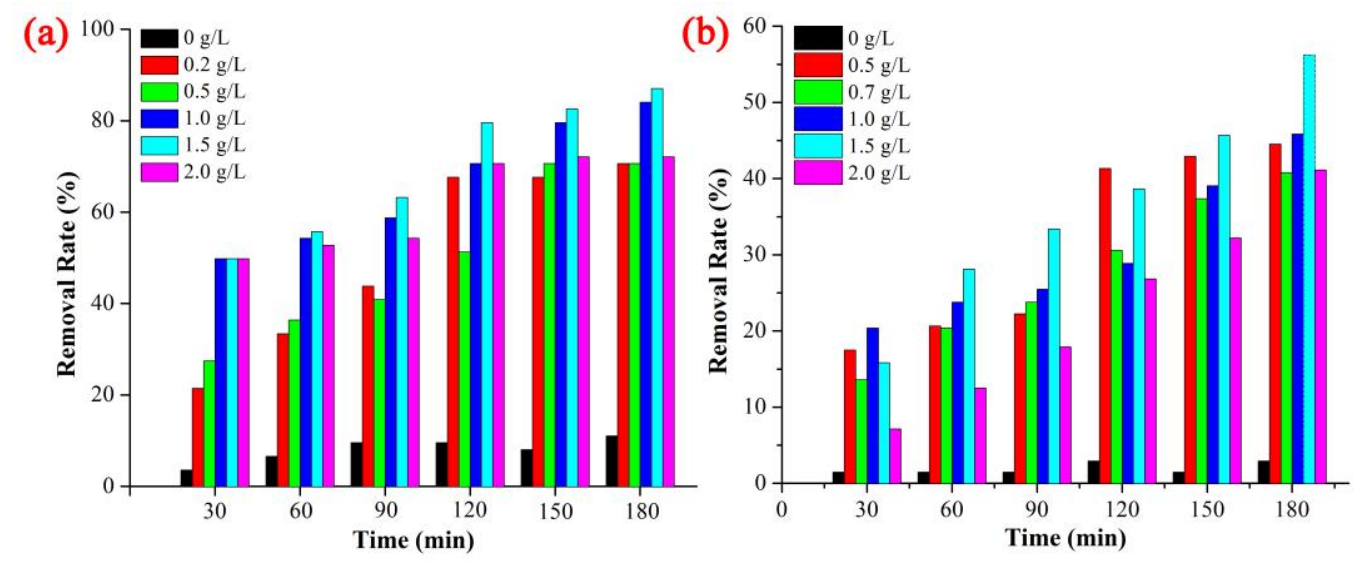

Figure 6. Effect of ZnO NPs dose on the photocatalytic degradation of MO (a) and PNP (b).

These results indicate that when the amount of catalyst is small, the concentration of catalyst in the reaction system is small, the adsorption capacity of the degraded material is weak, and the ultraviolet light of the system cannot be fully utilized. Therefore, the photocatalytic activity is poor, and the rate of pollutant degradation is low. With the increase in the amount of catalyst, the amount of adsorption on the degraded materials increases, and the number of electron-hole pairs generated by $\mathrm{ZnO}$ increases, which is beneficial for improving the photocatalytic activity of $\mathrm{ZnO}$ in the photocatalytic reaction and the degradation rate of pollutants increases. However, when there is too much catalyst, the turbidity of the solution increases and the transmittance decreases, and the ZnO NPs cause the reflection of incident light, which affects the utilization rate of the light source; the number of electron-hole pairs decrease, leading to the photocatalytic activity of the catalyst and the degradation rate of pollutants.

In this paper, the pseudo-first-order and pseudo-second-order kinetics models were used to evaluate the degradation kinetics of $\mathrm{MO}$ and PNP with different doses of $\mathrm{ZnO}$ NPs [25]. The kinetics equations were as follows:

$$
\begin{gathered}
\ln \left(C_{t} / C_{0}\right)=-k_{1^{\prime} a p p} t+b_{1} \\
1 / C_{t}=-k_{2^{\prime} \text { app }} t+b_{2}
\end{gathered}
$$

where $k_{1^{\prime} \text { app }}$ and $k_{2^{\prime} \text { app }}$ are the degradation kinetic constants of the pseudo-first-order kinetics model and pseudo-second-order kinetics model, $C_{0}$ is the initial concentration of $\mathrm{MP}$ and PNP $(\mathrm{mg} / \mathrm{L}), C_{t}$ is the actual concentration of MO and PNP $(\mathrm{mg} / \mathrm{L})$ at a certain reaction time $t(\mathrm{~min}), b_{1}$ and $b_{2}$ are the constants for the pseudo-first-order kinetics model and pseudo-second-order kinetics model.

Figure 7 and Table 2 showed the photocatalytic degradation kinetics results of $\mathrm{MO}$ and PNP using ZnO NPs as a photocatalyst. The results indicated both the pseudofirst-order kinetics model and pseudo-second-order kinetics model were not represented in the photocatalytic degradation behaviours of MO and PNP using ZnO NPs as a photocatalyst. The maximum values of kinetics were $0.0128 \mathrm{~min}^{-1}$ (MO, pseudo-firstorder kinetics, $\mathrm{ZnO}$ dose $=1.5 \mathrm{~g} / \mathrm{L}), 0.0049(\mathrm{mg} / \mathrm{L})^{-1} \cdot \mathrm{min}^{-1}(\mathrm{MO}$, pseudo-second-order kinetics, $\mathrm{ZnO}$ dose $=1.5 \mathrm{~g} / \mathrm{L}), 0.0042 \mathrm{~min}^{-1}(\mathrm{PNP}$, pseudo-first-order kinetics, $\mathrm{ZnO}$ dose $=1.5 \mathrm{~g} / \mathrm{L}$ ), and $0.0004(\mathrm{mg} / \mathrm{L})^{-1} \cdot \mathrm{min}^{-1}$ (PNP, pseudo-second-order kinetics, $\mathrm{ZnO}$ dose $=1.5 \mathrm{~g} / \mathrm{L})$, respectively. 
(a)

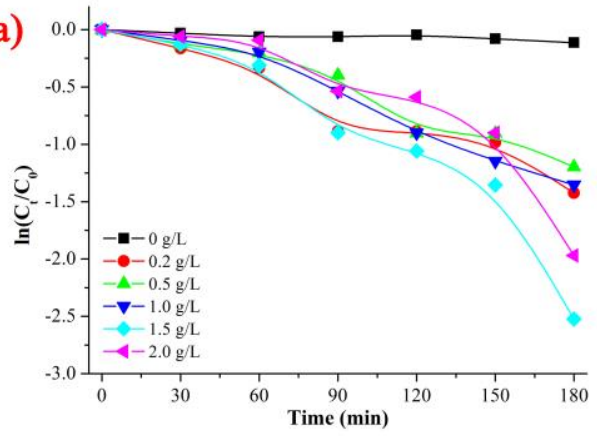

(b)

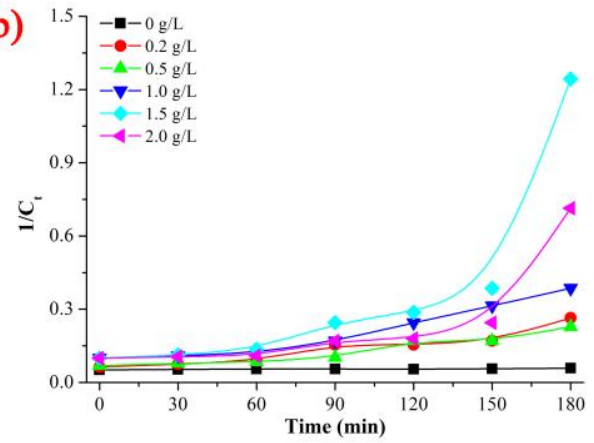

(c)

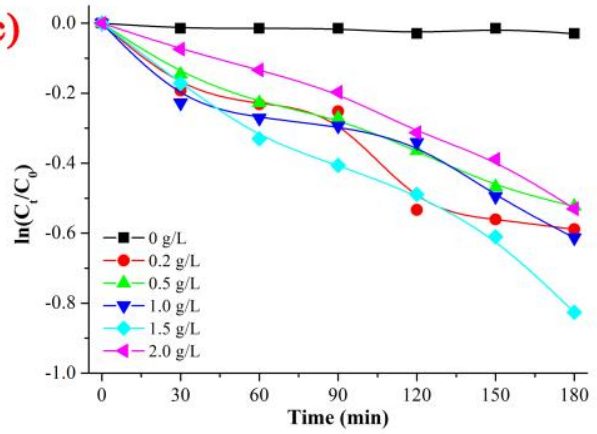

(d)

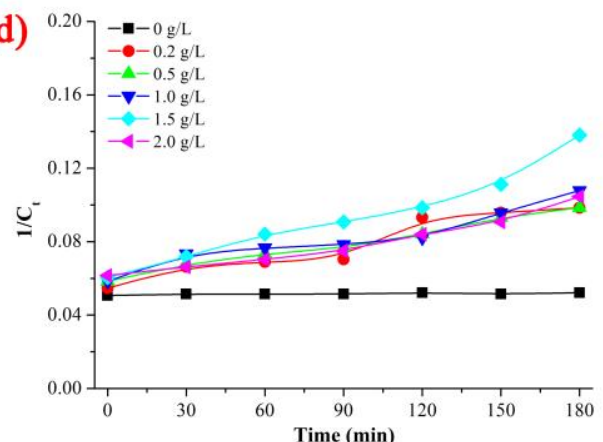

Figure 7. Pseudo-first-order kinetics model and pseudo-second-order kinetics model of $\mathrm{MO}(\mathbf{a}, \mathbf{b})$ and PNP (c,d) using ZnO NPs.

Table 2. Pseudo-first-order and pseudo-second-order kinetics of MO and PNP using ZnO NPs.

\begin{tabular}{|c|c|c|c|c|c|}
\hline \multirow[b]{2}{*}{ Pollutant } & \multirow{2}{*}{$\begin{array}{c}\text { ZnO NPs Dose } \\
(\mathrm{g} / \mathrm{L})\end{array}$} & \multicolumn{2}{|c|}{ Pseudo-First-Order } & \multicolumn{2}{|c|}{ Pseudo-Second-Order } \\
\hline & & $\begin{array}{c}k_{1^{\prime} a p p} \\
\left(\min ^{-1}\right)\end{array}$ & $\mathbf{R}^{2}$ & $\begin{array}{c}k_{2^{\prime} a p p} \\
\left((\mathrm{mg} / \mathrm{L})^{-1} \cdot \min ^{-1}\right)\end{array}$ & $\mathbf{R}^{2}$ \\
\hline \multirow{6}{*}{$\mathrm{MO}$} & 0 & 0.0005 & 0.8131 & 0.00003 & 0.8129 \\
\hline & 0.2 & 0.0077 & 0.9454 & 0.0010 & 0.8935 \\
\hline & 0.5 & 0.0070 & 0.9444 & 0.0009 & 0.9028 \\
\hline & 1.0 & 0.0082 & 0.9688 & 0.0017 & 0.9268 \\
\hline & 1.5 & 0.0128 & 0.8966 & 0.0049 & 0.6219 \\
\hline & 2.0 & 0.0096 & 0.8109 & 0.0026 & 0.5965 \\
\hline \multirow{6}{*}{ PNP } & 0 & 0.0001 & 0.6120 & 0.000006 & 0.6114 \\
\hline & 0.5 & 0.0033 & 0.9218 & 0.0003 & 0.9206 \\
\hline & 0.7 & 0.0028 & 0.9838 & 0.0002 & 0.9889 \\
\hline & 1.0 & 0.0029 & 0.9230 & 0.0002 & 0.9206 \\
\hline & 1.5 & 0.0042 & 0.9788 & 0.0004 & 0.9534 \\
\hline & 2.0 & 0.0029 & 0.9804 & 0.0002 & 0.9575 \\
\hline
\end{tabular}

In this experiment, the ZnO NPs showed good photocatalytic stability. The photocatalytic degradation rate of $\mathrm{MO}$ decreased from $92 \%$ to $>80 \%$, and the degradation rate of PNP decreased from $56.2 \%$ to $>50 \%$ after 5 times of reuse, with $\mathrm{ZnO}$ dose $=1.5 \mathrm{~g} / \mathrm{L}$.

\subsection{Photocatalytic Mechanism of $\mathrm{ZnO} N \mathrm{NPS}_{\mathrm{s}}$}

The band structure of the ZnO NPs consists of a low-energy valence band filled with electrons and a high-energy conduction band not filled with electrons, and there are gaps between the valence band and conduction band. When the $\mathrm{ZnO}$ photocatalyst is irradiated by light with an energy greater than or equal to the band gap, the electron absorption energy in the valence band is excited to transition to the conduction band, and the corresponding holes are generated in the valence band, forming electron-hole pairs [26-28]. The electron-hole pair migrates to the particle surface under the action of 
a space electric field. The hole can react with $\mathrm{H}_{2} \mathrm{O}$ and $\mathrm{OH}^{-}$to generate the hydroxyl radical $\cdot \mathrm{OH}$, and the electron can react with $\mathrm{O}_{2}$ to generate the superoxide radical $\cdot \mathrm{O}_{2}{ }^{-}$. . $\mathrm{OH}$ and $\cdot \mathrm{O}_{2}{ }^{-}$are the key reactive oxygen species (ROS) in the photocatalytic progress of $\mathrm{ZnO}$ NPs. These ROS (.OH and $\mathrm{O}_{2}^{-}$) have strong oxidation abilities and can react with organic pollutants. The pollutant then degrades into $\mathrm{CO}_{2}, \mathrm{H}_{2} \mathrm{O}$, and other substances [29]. Figure 8 illustrates the entire process clearly. The specific reaction process is shown in the following equations:

$$
\begin{gathered}
\mathrm{ZnO}+\text { Irradiation } \rightarrow \mathrm{ZnO}\left(\mathrm{e}^{-}+\mathrm{h}^{+}\right) \\
\mathrm{H}_{2} \mathrm{O} / \mathrm{OH}^{-}+\mathrm{h}^{+} \rightarrow \cdot \mathrm{OH} \\
\mathrm{O}_{2}+\mathrm{e}^{-} \rightarrow \cdot \mathrm{O}_{2}^{-} \\
\mathrm{MO} / \mathrm{PNP}+\mathrm{ROS} \rightarrow \mathrm{H}_{2} \mathrm{O}+\mathrm{CO}_{2}
\end{gathered}
$$

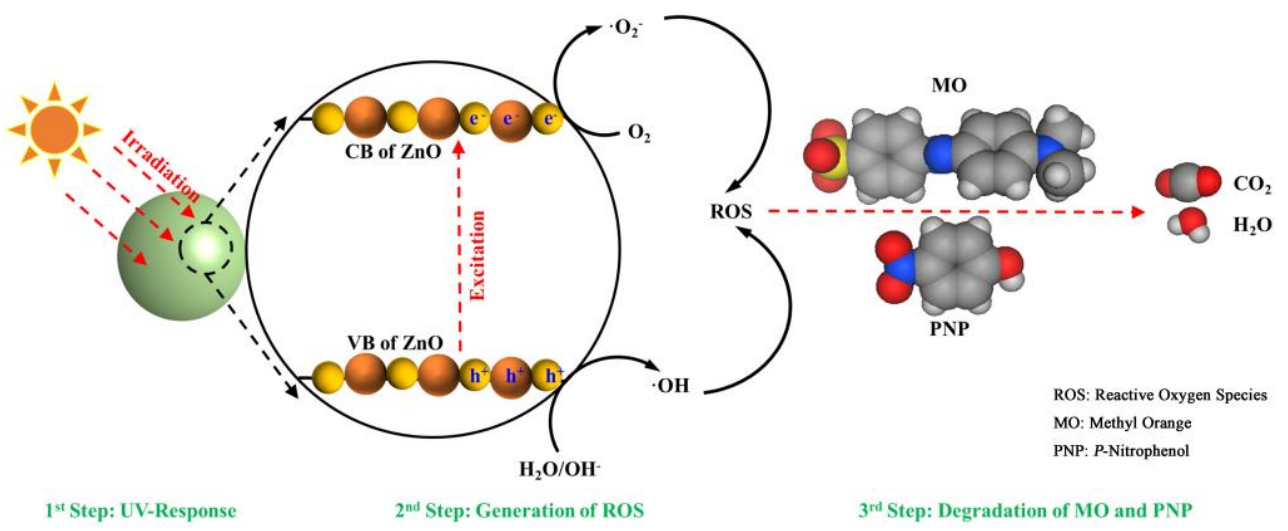

Figure 8. Photocatalytic mechanism of ZnO NPs.

\subsection{Degradation Pathways of $M O$ and PNP}

The MO oxidation reaction is divided into three stages: the first is the cleavage of the azo bond, which leads to the formation of aromatic intermediate products with conjugated structures, such as 2,5-nitrophenol, PNP, hydroquinone, and quinone. The sulfonic acid is simultaneously reduced to sulfinic acid. This process can be summarized as bondbreaking oxidation. The second stage is the ring-opening of the aromatic intermediates, which produces various short-chain carboxylic acids, and some intermediates lose amine groups and add a hydroxyl group to the benzene ring [30]. The final stage is the complete oxidation process, where organic matter is completely oxidized to $\mathrm{CO}_{2}, \mathrm{H}_{2} \mathrm{O}$, and other small molecules by superoxide radicals [31]. Figure 9 shows the possible degradation pathway of MO. In the first stage, the $\mathrm{N}=\mathrm{N}$ azo bond is broken to form an $\mathrm{HN}-\mathrm{NH}$ single bond. The second stage is demethylation, in which a $-\mathrm{CH}_{3}$ group is removed from the $\mathrm{N}$. The third stage is the breaking of the HN-NH single bond, and all the methyl groups on the right side of the molecule fall off and become phenolic organic compounds. Finally, all of these small organic acids are mineralized into $\mathrm{H}_{2} \mathrm{O}$ and $\mathrm{CO}_{2}$ under the action of superoxide free radicals. 

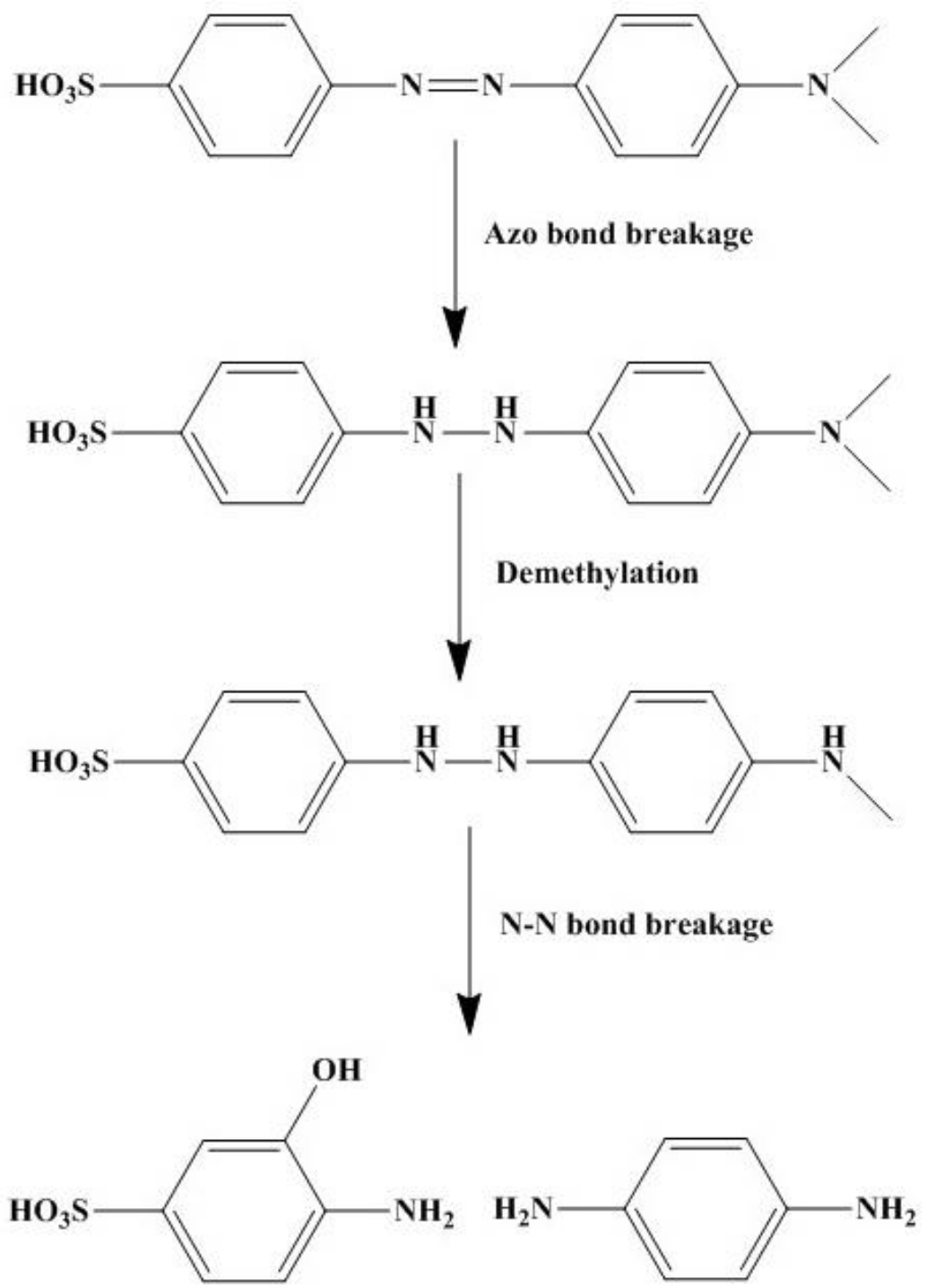

Figure 9. Degradation pathway of MO.

The degradation path of PNP is as follows: the electron-hole pair generated by the excitation of $\mathrm{ZnO}$ has a strong oxidizing effect on free radicals. The initial step of degradation is the electrophilic addition of hydroxyl radicals to the matrix to generate $p$-nitrogen. The catechol, benzoquinone, and nitrogen-containing compounds, and some of the nitro groups $\left(-\mathrm{NO}_{2}\right)$ in PNP are reduced to amino groups $\left(-\mathrm{NH}_{2}\right)$. The subsequent hydroxylation of the oxidation byproducts produces polyhydroxy cyclic compounds, such as pyrogallol and 2,3-dihydroxy-1,4-benzoquinone. These compounds have low stability and therefore undergo oxidative ring-opening reactions to form unsaturated dibasic acids. A further decarboxylation reaction leads to the release of carbon dioxide and shortens the carbon chain, and finally, these small acidic molecules are converted into $\mathrm{CO}_{2}$ and $\mathrm{H}_{2} \mathrm{O}$ [32] Figure 10 shows three possible degradation pathways of PNP. First, PNP loses nitro groups $\left(-\mathrm{NO}_{3}\right)$ to form phenol, which then undergoes ring-opening to form oxalic acid under the action of superoxide radicals. In the second pathway, hydroxyl groups replace the nitro groups $\left(-\mathrm{NO}_{3}\right)$ on the PNP to form hydroquinone, which is then oxidized by carbonylation under the action of superoxide radicals to form $p$-benzoquinone, and finally, the ring is opened to form oxalic acid. The third pathway is the addition of $-\mathrm{OH}$ to the hydroxyl ortho of PNP and subsequent removal of the nitro groups $\left(-\mathrm{NO}_{3}\right)$ under the action of superoxide radicals; finally, the ring is opened to form oxalic acid. Eventually, oxalic acid is completely mineralized into $\mathrm{H}_{2} \mathrm{O}$ and $\mathrm{CO}_{2}$ by the superoxide radicals. 


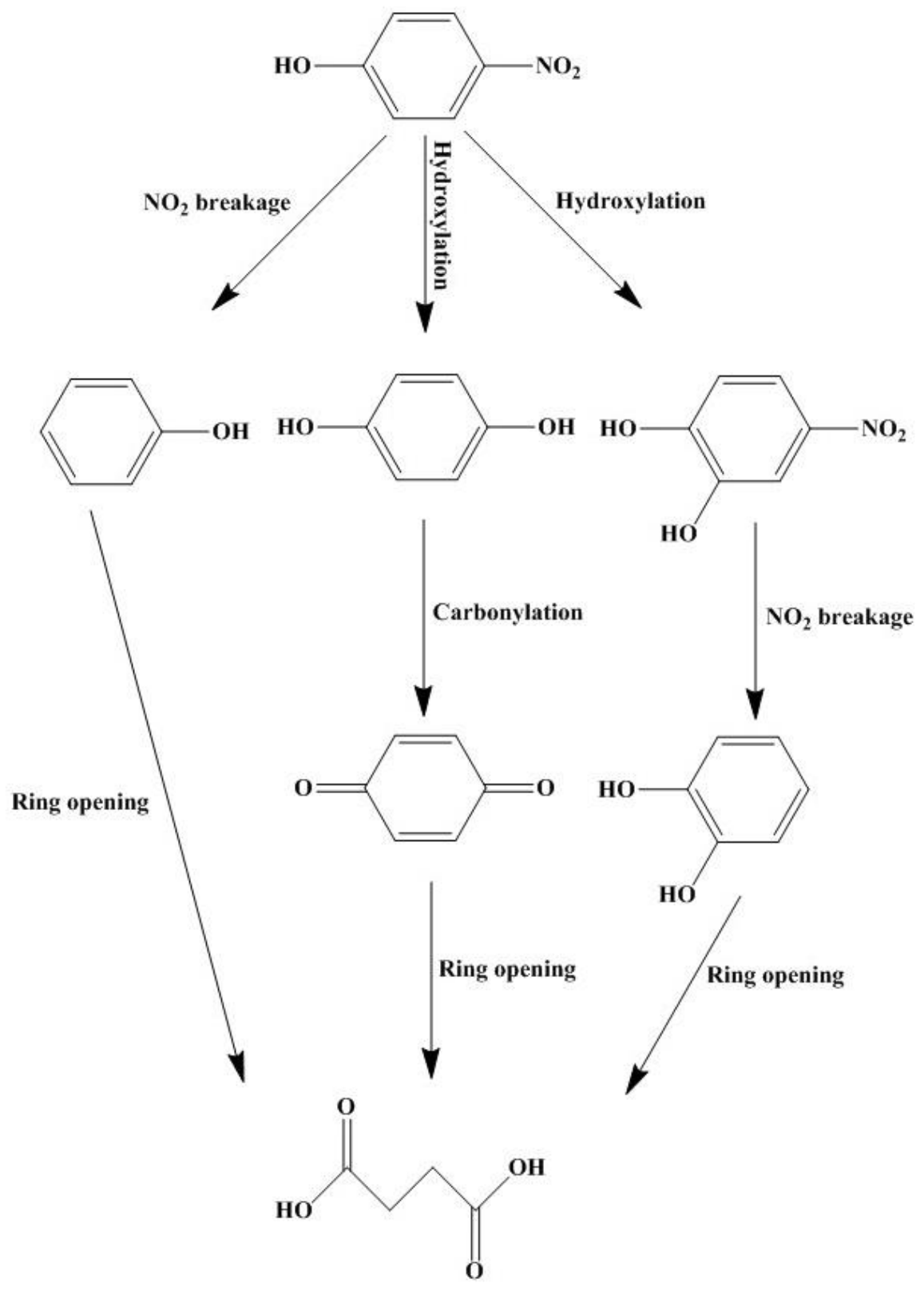

Figure 10. Degradation pathway of MO.

\subsection{Environmental Impact}

As a semiconductor photocatalyst with excellent properties, nano- $\mathrm{ZnO}$ has been widely studied by researchers in the fields of materials, catalysis, energy environment, and optics. Moreover, $\mathrm{ZnO}$ nanostructures with different morphologies have different physical and chemical properties, and the effects of applying them to photocatalytic degradation of pollutants are also different. The ZnO NPs prepared in this article are simple to prepare, and it is also easy to obtain the materials used in preparation. No surfactant or structure-directing agent is introduced, and the whole preparation process is relatively environmentally friendly. The ZnO NPs prepared in this paper have high photocatalytic performance. The photocatalytic degradation rates of $\mathrm{MO}$ and PNP can reach $96 \%$ and $60.9 \%$ in $180 \mathrm{~min}$, respectively, and have good degradation effects. Tables 3 and 4 summarize the degradation effects of the different photocatalysts on MO and PNP. 
Table 3. Summary of the degradation of MO by different photocatalysts.

\begin{tabular}{|c|c|c|c|c|c|}
\hline Catalysts & Preparation & Light & Time & $\begin{array}{l}\text { Photocatalytic } \\
\text { Activity }\end{array}$ & References \\
\hline $\mathrm{ZnO} N \mathrm{NP}$ & solvothermal & UV & $180 \mathrm{~min}$ & $92 \%$ & This work \\
\hline $\mathrm{ZnO}$ balls & biosynthesis & solar irradiation & $100 \mathrm{~min}$ & $100 \%$ & [33] \\
\hline leaf-like $\mathrm{ZnO}$ & microwave heating & $1000 \mathrm{~W}$, Xe lamp & $60 \mathrm{~min}$ & $69.5 \%$ & [34] \\
\hline pseudo-spherical $\mathrm{ZnO}$ & precipitation & $300 \mathrm{~W}$, mercury lamp & $120 \mathrm{~min}$ & $50 \%$ & [35] \\
\hline $\mathrm{ZnO} /$ bamboo charcoal & precipitation & UV & $40 \mathrm{~min}$ & $92.3 \%$ & [12] \\
\hline $\mathrm{Fe}_{3} \mathrm{O}_{4} / \mathrm{ZnO}-\mathrm{GO}$ & chemical & $\begin{array}{l}300 \mathrm{~W} \\
\text { Xe lamp }\end{array}$ & $30 \min$ & $93 \%$ & {$[36]$} \\
\hline $\mathrm{TiO}_{2} / \mathrm{g}-\mathrm{C}_{3} \mathrm{~N}_{4} / \mathrm{MoS}_{2}$ & solvothermal & Xe lamp & $60 \mathrm{~min}$ & $96.5 \%$ & [37] \\
\hline $\mathrm{TiO}_{2} /$ biochar composite & hydrolysis & $\begin{array}{l}500 \mathrm{~W}, \\
\text { Hg lamp }\end{array}$ & $160 \mathrm{~min}$ & $96.88 \%$ & [38] \\
\hline Cd-doped $\mathrm{WO}_{3} @ g-\mathrm{C}_{3} \mathrm{~N}_{4}$ & metal-doped & $\begin{array}{l}300 \mathrm{~W} \\
\text { Xe lamp }\end{array}$ & $80 \mathrm{~min}$ & $42.90 \%$ & [39] \\
\hline $\mathrm{Au} / \mathrm{TiO}_{2}$ nanoparticles & microwave-polyol & UV & $20 \mathrm{~min}$ & $96 \%$ & [40] \\
\hline
\end{tabular}

Table 4. Summary of the degradation of PNP with different photocatalysts.

\begin{tabular}{|c|c|c|c|c|c|}
\hline Catalysts & Preparation & Light & Time & $\begin{array}{c}\text { Photocatalytic } \\
\text { Activity }\end{array}$ & References \\
\hline $\mathrm{ZnO} N \mathrm{NP}$ & solvothermal & UV & $180 \mathrm{~min}$ & $56.2 \%$ & This work \\
\hline $\mathrm{ZnO}$ & biologically & UV & $480 \mathrm{~min}$ & $82.5 \%$ & [41] \\
\hline $\mathrm{TiO}_{2}$-hydroxyapatite & reflux method & UV & $660 \mathrm{~min}$ & $100 \%$ & [42] \\
\hline $\mathrm{SnO}_{2}-\mathrm{rGO}$ & photochemical & UV & $80 \mathrm{~min}$ & $95.6 \%$ & [43] \\
\hline $\mathrm{La}-\mathrm{ZnO}$ & hydrothermal & UV & $150 \mathrm{~min}$ & $92 \%$ & [44] \\
\hline Self-assembled carbon nitride & template-free & $\begin{array}{c}500 \mathrm{~W} \\
\text { Hg lamp }\end{array}$ & $80 \mathrm{~min}$ & $90 \%$ & [45] \\
\hline $\mathrm{g}-\mathrm{C}_{3} \mathrm{~N}_{4} @{ }^{\mathrm{H} / \mathrm{S}} \mathrm{MOF} \mathrm{NCs}$ & sonochemical & Visible light & $120 \mathrm{~min}$ & $75 \%$ & {$[46]$} \\
\hline
\end{tabular}

\section{Conclusions}

In summary, this article describes a simple solvothermal method of preparing $\mathrm{ZnO}$ NP photocatalysts with spherical morphology and excellent performance. The preparation method is simple, the materials used for preparation are easy to obtain, no surfactant or structure directing agent is introduced, and the whole preparation process is relatively environmentally friendly. According to the SEM images, the size of the ZnO NPs was uniform, with a diameter of approximately 25-40 nm. Under ultraviolet light irradiation, both MO and PNP showed higher degradation efficiency in aqueous solution. This study also investigated the effects of different doses on the photocatalytic activity and explained the photocatalytic mechanism of $\mathrm{ZnO}$ and the degradation pathways of two organic pollutants. The maximum values of kinetics were $0.0128 \mathrm{~min}^{-1}(\mathrm{MO}$, pseudo-first-order kinetics, $\mathrm{ZnO}$ dose $=1.5 \mathrm{~g} / \mathrm{L}), 0.0049(\mathrm{mg} / \mathrm{L})^{-1} \cdot \mathrm{min}^{-1}(\mathrm{MO}$, pseudo-second-order kinetics, $\mathrm{ZnO}$ dose $=1.5 \mathrm{~g} / \mathrm{L}), 0.0042 \mathrm{~min}^{-1}$ (PNP, pseudo-first-order kinetics, $\mathrm{ZnO}$ dose $=1.5 \mathrm{~g} / \mathrm{L}$ ) and $0.0004(\mathrm{mg} / \mathrm{L})^{-1} \cdot \mathrm{min}^{-1}(\mathrm{PNP}$, pseudo-second-order kinetics, $\mathrm{ZnO}$ dose $=1.5 \mathrm{~g} / \mathrm{L})$, respectively. Therefore, $\mathrm{ZnO}$ NPs have great potential in the field of wastewater treatment. They can be used as photocatalysts to remove MO and PNP and solve environmental problems.

Author Contributions: Conceptualization, Y.W.; methodology, Y.W., C.Y. and Y.L. (Yonglin Liu); validation, Y.W., Y.F. and F.D.; investigation, Y.W., Y.Q. and H.Z.; resources, Y.L. (Yuzhen Liu) and W.W.; data curation, Y.W.; writing-original draft preparation, Y.W., C.Y. and Y.L. (Yonglin Liu); writing-review and editing, Y.L. (Yuzhen Liu) and W.W.; supervision, Y.L. (Yuzhen Liu) and W.W.; project administration, W.W.; funding acquisition, F.D., W.W. and F.D. All authors have read and agreed to the published version of the manuscript.

Funding: This work was supported by the National Natural Science Foundation of China (41672340 and 52173286). 
Institutional Review Board Statement: Not applicable.

Informed Consent Statement: Not applicable.

Data Availability Statement: No new data were created or analyzed in this study. Data sharing is not applicable to this article.

Acknowledgments: The authors would like to express their sincere gratitude to the unidentified reviewers and editors for their generous efforts in reviewing and improving the manuscript.

Conflicts of Interest: The authors declare no conflict of interest.

\section{References}

1. Fujishima, A.; Honda, K. Electrochemical photolysis of water at a semiconductor electrode. Nature 1972, 238, 37-38. [CrossRef] [PubMed]

2. Gole, J.L.; Stout, J.D.; Burda, C.; Lou, Y.B.; Chen, X.B. Highly efficient formation of visible light tunable TiO $\mathrm{T}_{2-\mathrm{x}} \mathrm{N}_{\mathrm{x}}$ photocatalysts and their transformation at the nanoscale. J. Cheminform. 2004, 108, 1230-1240.

3. Mukhopadhyay, S.; Das, P.P.; Maity, S.; Ghosh, P.; Devi, P.S. Solution grown ZnO rods: Synthesis, characterization and defect mediated photocatalytic activity. Appl. Catal. B-Environ. 2015, 165, 128-138. [CrossRef]

4. Dindar, B.; Icli, S. Unusual photoreactivity of zinc oxide irradiated by concentrated sunlight. J. Photochem Photobiol. A 2001, 140, 263-268. [CrossRef]

5. Yeber, M.C.; Rodriguez, J.; Freer, J.; Baeza, J.; Duran, N.; Mansilla, H.D. Advanced oxidation of a pulp mill bleaching wastewater. Chemosphere 1999, 39, 1679-1688. [CrossRef]

6. Song, K.Y.; Park, M.K.; Kwon, Y.T.; Lee, H.W.; Chung, W.J.; Lee, W.I. Preparation of transparent particulate $\mathrm{MoO}_{3} / \mathrm{TiO}_{2}$ and $\mathrm{WO}_{3} / \mathrm{TiO}_{2}$ films and their photocatalytic properties. Chem. Mater. 2001, 13, 2349-2355. [CrossRef]

7. Chen, H.M.; Chen, C.K.; Chang, Y.C.; Tsai, C.W.; Liu, R.S.; Hu, S.F.; Chang, W.S.; Chen, K.H. Quantum dot monolayer sensitized $\mathrm{ZnO}$ nanowire-array photoelectrodes: True efficiency for water splitting. Angew. Chem. Int. Ed. 2010, 49, 5966-5969. [CrossRef]

8. Chu, H.O.; Wang, Q.; Shi, Y.J.; Song, S.G.; Liu, W.G.; Zhou, S.; Gibson, D.; Alajlani, Y.; Li, C. Structural, optical properties and optical modelling of hydrothermal chemical growth derived ZnO nanowires. T. Nonferr. Metal. Soc. 2020, 30, 191-199. [CrossRef]

9. Baskoutas, S. Zinc oxide nanostructures: Synthesis and characterization. Materials 2018, 11, 873. [CrossRef]

10. Luevano-Hipolito, E.; Martinez-de la Cruz, A.; Cuellar, E.L. Performance of ZnO synthesized by sol-gel as photocatalyst in the photooxidation reaction of NO. Environ. Sci. Pollut. Res. 2016, 24, 6361-6371. [CrossRef]

11. Yu, W.L.; Zhang, J.F.; Peng, T.Y. New insight into the enhanced photocatalytic activity of N-, C- and S-doped ZnO photocatalysts. Appl. Catal. B-Environ. 2016, 181, 220-227. [CrossRef]

12. Zhou, Y.L.; Hu, Z.B.; Tong, M.X.; Zhang, Q.L.; Tong, C.Q. Preparation and photocatalytic performance of bamboo-charcoalsupported nano-ZnO composites. Mater. Sci. 2018, 24, 49-52. [CrossRef]

13. Umar, A.; Chauhan, M.S.; Chauhan, S.; Kumar, R.; Kumar, G.; Al-Sayari, S.A.; Hwang, S.W.; Al-Hajry, A. Large-scale synthesis of $\mathrm{ZnO}$ balls made of fluffy thin nanosheets by simple solution process: Structural, optical and photocatalytic properties. J. Colloid. Interf. Sci. 2011, 363, 521-528. [CrossRef]

14. Cheng, P.F.; Wang, Y.L.; Xu, L.P.; Sun, P.; Su, Z.S.; Jin, F.M.; Liu, F.M.; Sun, Y.F.; Lu, G.Y. High specific surface area urchin-like hierarchical $\mathrm{ZnO}-\mathrm{TiO}_{2}$ architectures: Hydrothermal synthesis and photocatalytic properties. Mater. Lett. 2016, $175,52-55$. [CrossRef]

15. Zhang, P.; Li, B.B.; Zhao, Z.B.; Yu, C.; Hu, C.; Wu, S.J.; Qiu, J.S. Furfural-induced hydrothermal synthesis of ZnO@C gemel hexagonal microrods with enhanced photocatalytic activity and stability. ACS Appl. Mater. Interfaces 2014, 6, 8560-8566. [CrossRef] [PubMed]

16. Rashidi, H.; Ahmadpour, A.; Bamoharram, F.F.; Zebarjad, S.M.; Heravi, M.M.; Tayari, F. Controllable one-step synthesis of ZnO nanostructures using molybdophosphoric acid. Chem. Pap. 2013, 68, 516-524. [CrossRef]

17. Chen, X.B.; Shen, S.H.; Guo, L.J.; Mao, S.S. Semiconductor-based photocatalytic hydrogen generation. Chem. Rev. 2010, 110, 6503-6570. [CrossRef]

18. Tian, L.; Yang, X.F.; Lu, P.; Williams, I.D.; Wang, C.H.; Ou, S.Y.; Liang, C.L.; Wu, M.M. Hollow single-crystal spinel nanocubes: The case of zinc cobalt oxide grown by a unique kirkendall effect. Inorg. Chem. 2008, 47, 5522-5524. [CrossRef]

19. Mohamed, M.A.; Salleh, W.N.W.; Jaafar, J.; Ismail, A.F. Structural characterization of N-doped anatase-rutile mixed phase TiO 2 nanorods assembled microspheres synthesized by simple sol-gel method. J. Sol-Gel. Sci. Technol. 2015, 74, 513-520. [CrossRef]

20. Akir, S.; Hamdi, A.; Addad, A.; Coffinier, Y.; Boukherroub, R.; Omrani, A.D. Facile synthesis of carbon-ZnO nanocomposite with enhanced visible light photocatalytic performance. Appl. Surf. Sci. 2017, 400, 461-470. [CrossRef]

21. Osman, H.; Su, Z.; Ma, X.L.; Liu, S.S.; Liu, X.Y.; Abduwayit, D. Synthesis of ZnO/C nanocomposites with enhanced visible light photocatalytic activity. Ceram. Int. 2016, 42, 10237-10241. [CrossRef]

22. Yang, C.X.; Wang, X.N.; Ji, Y.J.; Ma, T.; Zhang, F.; Wang, Y.Q.; Ci, M.W.; Chen, D.T.; Jiang, A.X.; Wang, W.L. Photocatalytic degradation of methylene blue with ZnO@C nanocomposites: Kinetics, mechanism, and the inhibition effect on monoamine oxidase A and B. Nanoimpact 2019, 15, 100174. [CrossRef] 
23. Iqbal, T.; Zahra, S.K.; Khan, M.A.R.; Shafique, M.; Raza, S.R.A.; Andleeb, S. Microplasma-assisted electrochemical synthesis of ZnO nanostructures for photocatalytic and antibacterial applications. Phys. Scripta 2021, 96, 125801. [CrossRef]

24. Lopez-Munoz, M.J.; Revilla, A.; Alcalde, G. Brookite $\mathrm{TiO}_{2}$-based materials: Synthesis and photocatalytic performance in oxidation of methyl orange and As(III) in aqueous suspensions. Catal. Today 2015, 240, 138-145. [CrossRef]

25. Pinna, M.; Binda, G.; Altomare, M.; Marelli, M.; Dossi, C.; Monticelli, D.; Spanu, D.; Recchia, S. Biochar nanoparticles over TiO 2 nanotube arrays: A green Co-catalyst to boost the photocatalytic degradation of organic pollutants. Catalysts 2021, 11, 1048. [CrossRef]

26. Liu, S.; Su, Z.L.; Liu, Y.; Yi, L.Y.; Chen, Z.L.; Liu, Z.Z. Mechanism and purification effect of photocatalytic wastewater treatment using graphene oxide-doped titanium dioxide composite nanomaterials. Water-Sui. 2021, 13, 1915. [CrossRef]

27. Wang, Z.C.; Hou, Q.Y.; Guan, Y.Q.; Sha, S.L.; Chen, M.X. Influence of $(\mathrm{Li} / \mathrm{Na} / \mathrm{K})$ doping and point defect $\left(\mathrm{V}_{\mathrm{Al}}, \mathrm{H}_{\mathrm{i}}\right)$ on the magnetic and photocatalytic performance of AlN: A first-principles study. Mater. Chem. Phys. 2021, 268, 124706. [CrossRef]

28. Ong, C.B.; Ng, L.Y.; Mohammad, A.W. A review of ZnO nanoparticles as solar photocatalysts: Synthesis, mechanisms and applications. Renew. Sust. Energ. Rev. 2018, 81, 536-551. [CrossRef]

29. Ochiai, T.; Fujishima, A. Photoelectrochemical properties of $\mathrm{TiO}_{2}$ photocatalyst and its applications for environmental purification. J. Photochem. Photobiol. C 2012, 13, 247-262. [CrossRef]

30. Pargoletti, E.; Pifferi, V.; Falciola, L.; Facchinetti, G.; Depaolini, A.R.; Davoli, E.; Marelli, M.; Cappelletti, G. A detailed investigation of $\mathrm{MnO}_{2}$ nanorods to be grown onto activated carbon. High efficiency towards aqueous methyl orange adsorption/degradation. Appl. Surf. Sci. 2019, 472, 118-126. [CrossRef]

31. Huang, F.M.; Chen, L.; Wang, H.L.; Feng, T.Z.; Yan, Z.C. Degradation of methyl orange by atmospheric DBD plasma: Analysis of the degradation effects and degradation path. J. Electrostat. 2012, 70, 43-47. [CrossRef]

32. Dai, Q.Z.; Lei, L.C.; Zhang, X.W. Enhanced degradation of organic wastewater containing $p$-nitrophenol by a novel wet electrocatalytic oxidation process: Parameter optimization and degradation mechanism. Sep. Purif. Technol. 2008, 61, 123-129. [CrossRef]

33. Alharthi, M.N.; Ismail, I.; Bellucci, S.; Khdary, N.H.; Salam, M.A. Biosynthesis microwave-assisted of zinc oxide nanoparticles with ziziphus jujuba leaves extract: Characterization and photocatalytic application. Nanomater. Basel 2021, 11, 1682. [CrossRef] [PubMed]

34. Peng, F.; Zhu, H.; Wang, H.; Yu, H. Preparation of Ag-sensitized ZnO and its photocatalytic performance under simulated solar light. Korean J. Chem. Eng. 2007, 24, 1022-1026. [CrossRef]

35. Chen, C.C.; Liu, J.F.; Liu, P.; Yu, B.H. Investigation of photocatalytic degradation of methyl orange by using nano-sized ZnO catalysts. Adv. Chem. Eng. Sci. 2011, 1, 9-14. [CrossRef]

36. Feng, Q.; Li, S.Y.; Ma, W.H.; Fan, H.J.; Wan, X.H.; Lei, Y.; Chen, Z.J.; Yang, J.; Qin, B. Synthesis and characterization of Fe ${ }_{3} \mathrm{O}_{4} / \mathrm{ZnO}$ GO nanocomposites with improved photocatalytic degradation methyl orange under visible light irradiation. J. Alloys Compd. 2018, 737, 197-206. [CrossRef]

37. Zhang, W.P.; Xiao, X.Y.; Li, Y.; Zeng, X.Y.; Zheng, L.L.; Wan, C.X. Liquid-exfoliation of layered $\mathrm{MoS}_{2}$ for enhancing photocatalytic activity of $\mathrm{TiO}_{2} / g-\mathrm{C}_{3} \mathrm{~N}_{4}$ photocatalyst and DFT study. Appl. Surf. Sci. 2016, 389, 496-506. [CrossRef]

38. Lu, L.L.; Shan, R.; Shi, Y.Y.; Wang, S.X.; Yuan, H.R. A novel $\mathrm{TiO}_{2}$ /biochar composite catalysts for photocatalytic degradation of methyl orange. Chemosphere 2019, 222, 391-398. [CrossRef]

39. Abu Hanif, M.; Akter, J.; Islam, M.A.; Sapkota, K.P.; Hahn, J.R. Visible-light-driven enhanced photocatalytic performance using cadmium-doping of tungsten (VI) oxide and nanocomposite formation with graphitic carbon nitride disks. Appl. Surf. Sci. 2021, 565, 150541. [CrossRef]

40. Tsuji, M.; Matsuda, K.; Tanaka, M.; Kuboyama, S.; Uto, K.; Wada, N.; Kawazumi, H.; Tsuji, T.; Ago, H.; Hayashi, J. Enhanced photocatalytic degradation of methyl orange by $\mathrm{Au} / \mathrm{TiO}_{2}$ nanoparticles under neutral and acidic solutions. Chemistryselect 2018, 3, 1432-1438. [CrossRef]

41. Kadam, V.V.; Shanmugam, S.D.; Ettiyappan, J.P.; Balakrishnan, R.M. Photocatalytic degradation of $p$-nitrophenol using biologically synthesized ZnO nanoparticles. Environ. Sci. Pollut. Res. 2021, 28, 12119-12130. [CrossRef] [PubMed]

42. Gangarajula, Y.; Kedharnath, R.; Gopal, B. Investigation of photocatalytic activity of pure strontium hydroxyapatite and its Ti-substituted and $\mathrm{TiO}_{2}$ loaded forms. Appl. Catal. A-Gen. 2015, 506, 100-108. [CrossRef]

43. Chen, Y.; Sun, F.Q.; Huang, Z.J.; Chen, H.; Zhuang, Z.F.; Pan, Z.Z.; Long, J.F.; Gu, F.L. Photochemical fabrication of SnO 2 dense layers on reduced graphene oxide sheets for application in photocatalytic degradation of $p$-Nitrophenol. Appl. Catal. B-Environ. 2017, 215, 8-17. [CrossRef]

44. Lakshmi, K.; Kadirvelu, K.; Mohan, P.S. Photo-decontamination of $p$-nitrophenol using reusable lanthanum doped ZnO electrospun nanofiber catalyst. J. Mater. Sci.-Mater. Electron. 2018, 29, 12109-12117. [CrossRef]

45. Sun, J.W.; Xu, J.S.; Grafmueller, A.; Huang, X.; Liedel, C.; Algara-Siller, G.; Willinger, M.; Yang, C.; Fu, Y.S.; Wang, X.; et al. Self-assembled carbon nitride for photocatalytic hydrogen evolution and degradation of $p$-nitrophenol. Appl. Catal. B-Environ. 2017, 205, 1-10. [CrossRef]

46. Abazari, R.; Mahjoub, A.R.; Salehi, G. Preparation of amine functionalized g- $\mathrm{C}_{3} \mathrm{~N}_{4}{ }^{\mathrm{H}}{ }^{\mathrm{S}} \mathrm{S} \mathrm{MOF}$ NCs with visible light photocatalytic characteristic for 4-nitrophenol degradation from aqueous solution. J. Hazard. Mater. 2019, 365, 921-931. [CrossRef] 